\title{
UNA ISLA PROPIA: SOBRE UNA NOVELA POEMÁTICA DE AZORÍN
}

\author{
José María FERRI COLL \\ Universidad de Alicante
}

\section{RESUMEN}

La isla sin aurora es una hermosa novela poemática en que su autor colecciona sus ideas sobre la creación artística y el placer estético, que había ido desgranando a lo largo de su vida. La novela, más que un género literario, supuso para Azorín un género de vida. Y la poesía, antes que un molde concreto, representa la esencia de seres y objetos. El verdadero escritor debe dejar de lado lo anecdótico para alcanzar el verdadero y universal significado de nuestra especie. Cada artista tiene que emprender travesía a su propia isla. Y cuando consiga desembarcar allí, al menos, habrá aprendido que la obra más importante de un escritor es el mismo proceso de su realización.

Palabras clave: Novela poemática, La isla sin aurora, inspiración, creación artística

\section{ABSTRACT}

La isla sin aurora is a novel in which the author during his lifetime has collected his ideas regarding the creation of art and aesthetic pleasure. The novel became for Azorin not only a literary genre but also a genre of his life. Moreover, the poetry freed from a specific mould became the essence of people and things. The real writer has put aside the particular to delve into the universal meaning of our species. Each artist makes the journey through their particular island and upon arrival realizes that the most important work of the writer is the process of self discovery and self realisation.

Key Words: Inspiration, artistic creation, La isla sin aurora, novela poemática 
«La vida tiene retornos crueles» Azorín, El escritor (1941)

A buen seguro que, a principios de 1944, los lectores de Azorín se sorprenderían al llegar a sus manos La isla sin aurora, novela cuyo título ya llamaba la atención, si se compara éste con los rótulos habituales que el escritor de Monóvar elegía para sus libros (por recordar solo los de sus últimas novelas: El escritor, Capricho, El enfermo, María Fontán y Salvadora de Olbena). Azorín se ocupó precisamente de la manera de titular en el capítulo XX de su nueva novela: el escritor debe procurar que el marbete elegido para nombrar su obra no incurra en el defecto de la generalización, con el fin de que «cada cual, según su temperamento, según sus pasiones, saque de la narración la enseñanza que quiera» (p.196) ${ }^{1}$. El mismo sobresalto parece que sintieron los primeros reseñistas y comentaristas de la nueva novela del alicantino, que, en general, la recibieron con elogio. Y no solo aplaudieron la novela quienes la leyeron en sus primeros meses de vida pública: Mainer (1983: 179) afirmó en 1967 que la novela de Azorín era probablemente «uno de los libros más rotundamente bellos de estos últimos veinticinco años nacionales». Pero la sorpresa no solo se debía a la trayectoria novelística de Azorín, sino a la divergencia del relato del alicantino respecto de las tendencias novelísticas dominantes en aquel momento. Y no es que el escritor de Monóvar tratara de asuntos nuevos o desconocidos por los aficionados a sus libros, pues, como recordó en su día Martínez Cachero (1973: 129), las últimas novelas de Azorín redundan en motivos abordados con anterioridad. El propio autor confesó a Rafael Vázquez Zamora que le gustaba su nueva novela por ser algo distinto a lo suyo, y barruntaba asimismo que sorprendería a sus lectores habituales². Lo que llamaba la atención de la nueva entrega del maestro alicantino era precisamente la capacidad de síntesis que había tenido el autor a la hora de retomar su ideario estético, pero incardinado ahora en un relato poemático que se convierte en sí mismo en un arte de novelar, o mejor dicho en una brújula para artistas noveles. A sus setenta años, Azorín salía a la palestra con un relato cuyo argumento ya había esbozado en dos cuentos: el primero de 1923, La isla de la serenidad; y el segundo de 1926, La mayor emoción; y que entroncaba con una novela que había visto la luz dos años antes, Capricho. Cabe decir sobre esta última que fue propósito de Azorín escribir «la novela de lo indeterminado» en que los personajes intentan resolver sin éxito un problema que el autor les

1. Cito siempre por la edición de R. Londero (2006) indicando entre paréntesis la página.

2. Destino, 1 de abril de 1944. 
plantea: una persona cualquiera parte de Madrid con un millón de pesetas que deja en una casa de labor en medio del campo. Un redactor jefe, un crítico literario, un editorialista, y un reportero, entre otros, son los responsables de averiguar qué ocurrió al fin con ese dinero. Pero, en realidad, los lectores de Capricho apenas tendrán noticia de los acontecimientos que el autor les había anunciado en el planteamiento de la trama, porque cada uno de los personajes habla de sí mismo y de su entorno. Vale recordar el poco aprecio que Azorín sentía por la intriga; frente a la ineficacia de ésta sobresale el valor del matiz. Los mejores artistas, en el juicio de nuestro escritor, deben ser capaces de captar los matices. La realidad deja de existir y se confunde con lo imaginario. Azorín, amparándose en Berkeley, se pregunta si es posible deplorar la inexistencia del mundo.

La isla sin aurora apareció en un momento propicio para la novela. Como Emilio González López afirmó unos años más tarde, en 1947, la novela era el signo literario de la España de aquellos momentos. Un buen síntoma es que un año después se presentaron ciento veintidós obras al ya prestigioso premio Nadal, que había iniciado su andadura cuatro años antes; por el mismo tiempo, José Luis Vázquez Dodero hablaba de un segundo renacimiento de la novela española, hechos todos y palabras que prueban el auge del género en aquellos días. Pero ¿qué novelas se leían en la España de entonces y qué pautas estéticas dominaban el panorama narrativo de un país recién nacido a la pax franquista? ${ }^{3}$ La década del 40 había empezado a ofrecer al lector español cierta diversidad en el panorama novelístico, a pesar de que las editoriales de aquel tiempo se empeñaran en publicar traducciones de novelas extranjeras de diferentes autores, tales como Baring, Bromfield, etc., debido a la rentabilidad económica que les reportaban esas obras. Los cuatro éxitos editoriales españoles, según el autorizado parecer de Martínez Cachero (1979b: 120), fueron las novelas de Cela, La familia de Pascual Duarte (1942); de Ignacio Agustí, Mariona Rebull (1944); de Carmen Laforet, Nada (1945); y de Darío Fernández Flórez, Lola, espejo oscuro (1950). Aunque una mayoría considerable de novelistas españoles de aquellos años se consagró al cultivo del relato realista, no se puede obviar la existencia de otras tendencias narrativas. Los

3. El lector interesado en seguir el rastro de la novelística española de la década del 40 puede acogerse a los trabajos específicos de Martínez Cachero (1945, 1973: 116-119, y 1979a), F. Ynduráin (1952), Baquero Goyanes (1955), y Castellet (1963). Para un panorama de la literatura española en torno al año de 1950, véase Ramos Ortega y Pérez Bustamante (1995). Sobre La isla sin aurora, aparte de las reseñas citadas en la bibliografía, véanse E. G. de Nora (1958: 256-259), Mainer (1983 [1967]), Martínez Cachero (1960: 270-278), Albert (2001), y las introducciones a las ediciones de Londero (2006 y 2008).

Anales, 22, 2010, pp. 85-98 
novelistas considerados como referente del realismo fueron fundamentalmente Baroja, quien todavía vivía y seguía escribiendo, y a mayor distancia Galdós. En 1942 sorprendió a la crítica la esplendente obra de un escritor novel: La familia de Pascual Duarte, a la que siguieron dos años más tarde Pabellón de reposo y Nuevas andanzas y desventuras del Lazarillo de Tormes; en 1946, el escritor gallego presentó La colmena a la censura, que la rechazó, por lo que hubo de esperar a su publicación en Buenos Aires cinco años más tarde. Pero sin duda el estímulo mayor para los jóvenes novelistas de entonces fue el advenimiento del Premio Eugenio Nadal, que se falló por vez primera a principios de 1945 a favor de la opera prima de una jovencísima Carmen Laforet, que solo aquel año conoció tres ediciones. Nada compitió con otras veinticinco novelas que se presentaron al certamen. Repárese en el crecimiento considerable de obras que concurrían convocatoria tras convocatoria hasta llegar a los ciento veinte originales de 1950. Entre los ganadores del Nadal destacan escritores de la talla de Gironella, autor del best-seller Los cipreses creen en Dios (1953), y Delibes, que publicó La sombra del ciprés es alargada. En 1948 vieron la luz las novelas de Manuel Sánchez Camargo Nosotros, los muertos; y de Ana María Matute Los Abel. En los títulos mencionados se aprecia la impronta del llamado tremendismo, exacerbación de la realidad rayana en lo patológico. Si esta tendencia estética se afanó en presentar aquellos aspectos más deleznables de la condición humana sin reparar en el daño que tal muestra podía causar en la sensibilidad del lector, a su lado, aparecen otras obras de índole evasiva como la novela de que trata este artículo, La isla sin aurora (1944), o humorístico como las novelas de Jacinto Miquelarena Don Adolfo el libertino (1940), de inspiración ramoniana, cuyo humor radica en lo insólito y ridículo, pero siempre acompañado de una profunda ternura; de Claudio de la Torre Alicia al pie de los laureles (1940); de José María Álvarez Blázquez En el pueblo hay caras nuevas (1945), obra finalista del Nadal en el año en que lo ganó Laforet, deudora del humor de W. Fernández Flórez, que consigue mantener en vilo al lector hasta el final; el libro ganador del Nadal La luna ha entrado en casa (1945), de José Félix Tapia; y una esplendente novela de Antonio Mingote, Las palmeras de cartón (1948). Por aquellos mismos años cobró nombradía el hoy olvidado Zunzunegui, a quien la Academia galardonó con el Fastenrath en 1943 por su novela ¡Ay...estos hijos! En 1948 otra obra suya fue distinguida con el Premio Nacional de Literatura. Se trata de La úlcera, novela de humor en que don Lucas, el protagonista, muere aburrido y desocupado, una vez que se le ha curado la úlcera que él había cuidado durante años dedicándole buena parte de su tiempo. El balance de la producción novelística 
de la década del 40 resulta satisfactorio, a pesar de todos los obstáculos que la guerra, el exilio y la censura habían ido poniendo en su camino.

En ese ambiente se escribió La isla sin aurora, cuya adscripción al género de la novela poemática hace que la obra de Azorín sea ajena por completo al realismo imperante. Es más, difícilmente el lector encontrará en este libro puntos de contacto con la realidad. Conviene ahora repasar los rasgos básicos de la novela poemática que comparecen en el relato que nos ocupa ${ }^{4}$. Concebido este género, tal como lo entendía su promotor, Pérez de Ayala, en tres de sus novelas cortas publicadas en 1916, como fusión de novela, poesía, ensayo y drama, no extraña, pues, que Azorín echara mano de éste para la construcción de un relato en que conviven precisamente todos esos géneros. La novela poemática es asimismo el molde que permite al autor dar cuenta de una realidad compleja y contradictoria, cuyo traslado al arte a duras penas resiste una epidérmica generalización. En efecto, desde esta posición, el mundo se contempla poblado por una multiplicidad de seres contrarios que se armonizan desde una perspectiva superior. Azorín advierte al lector de que «cada uno de los tres personajes lleva sus sentimientos ocultos; cada cual tiene sus deseos, sus esperanzas y su ansia de olvidar lo que atosiga» (p. 162). Nuestros tres artistas no hallan barco que les conduzca a la isla sin aurora. Manuel Rodríguez intenta explicar al poeta por qué el capitán Pasquier se niega a emprender la travesía: «Son ustedes irreductiblemente incompatibles. Y lo son porque en tanto que ustedes beben ginebra marca Estrella, el capitán la bebe marca Llave. Comprendo que no podrán ustedes nunca amigar» (p. 144). El marino aconseja a los tres escritores que cedan, porque «al fin la diferencia entre la marca Estrella y la marca Llave no es tan grande como parece» (p. 146). En una de las escalas de la travesía, el poeta llega a tierra firme, donde halla una casa abandonada que evoca al visitante la superposición de dos mundos diferentes: «Oriente y Occidente: allí estaban, en esta casa del Bósforo, como condensados. El ambiente de uno y otro mundo, de una y otra civilización, ahora denso» (p. 158). Repárese, siguiendo el mismo argumento, en el episodio en que se narra la disputa entre la ondina y la sirena, debate que Azorín concluye lavándose las manos, y no solo metafóricamente:

¿A quién creer? ¿A la ondina o a la sirena? Como se ha visto, están una y otra contrapuntadas. Y si se apitonan mutuamente, ¿de quién será la culpa? No del autor. El autor, escribiendo a máquina, no puede mancharse los dedos de tinta. Se levanta, sin embargo, va al lavabo y se lava las manos (p. 296).

4. Aconsejo la lectura de M. Á. Lozano (1983: 202-220) a quien esté interesado en la caracterización de la novela poemática y la acunación del género por parte de Pérez de Ayala.

Anales, 22, 2010, pp. 85-98 
En 1928, Félix Vargas, en el prólogo de la novela del mismo nombre, aconseja a Azorín que se complazca en lo inorgánico, es decir en la realidad como ente informe y proteico. El poeta, el novelista y el dramaturgo analizan la realidad según los presupuestos estéticos que tiene por propios cada uno de ellos:

Presenciaron los tres personajes la deshecha borrasca; relampagueaba; caían rayos rectos o zigzagueantes; tronaba horrísonamente. El poeta encontró que la tempestad era un poquitín exagerada; no le servía. El novelista acaso pudiera utilizarla, con algunas modificaciones. El autor dramático torció el gesto y se encogió de hombros; tal vez, habiendo un naufragio, podría servir un náufrago para un episodio en el primer o en el tercer acto (p. 78).

Se persigue asimismo la plenitud humana, que consiste en «limitarse» a uno mismo, estado al que se llega cuando el hombre se conoce a sí mismo - «conocerse a sí mismo es el principio del dominarse» (p. 268); «¡Y cuántos hombres hay que mueren sin haberse descubierto a sí mismos!» (p. 142)-, y se somete a las normas - «la ley es dura, pero hay que cumplir la ley» (p. 240); «preciso es resignarse» (p. 94)-. La idea de limitación implica fortaleza: «limitarse es concentrar las fuerzas; es adquirir una profundidad, una intensidad, una fuerza de síntesis que antes no teníamos» (pp. 92 y 94); y también sabiduría: « ¡Limitarse para ser fuertes y para saber!» (p. 220). Azorín reflexiona con hondura sobre el concepto hasta llegar a la conclusión de que la inteligencia humana se puede calibrar en la medida en que somos capaces de usar «serenamente, con precaución, nuestra fuerza» (p. 230).

El realismo decimonónico es ineficaz porque no refleja la realidad esencial: «La intriga no es, después de todo, arte; el arte es la captación y gradación de los matices» (p. 92). Y añade Azorín todavía al respecto:

Si pudiéramos escrutar sus pensamientos, llegaríamos a descubrir que el poeta piensa también que, desde la remota lejanía, ha venido elaborándose a lo largo de las generaciones un tipo que había de condensar y resumir en sus versos la esencia prístina del mundo (p. 110).

La novela poemática, sin embargo, supera los cauces de la novela convencional para llegar a la intuición de la verdad: «[el poeta] no se entera de lo encimero e intuye lo profundo» (p. 126); sin que sea necesario que este proceso sea expresado atendiendo a criterios lógico-cronológicos («para expresar la realidad no es precisa la coherencia» [p. 110]; «en los sueños no hay ilación ni congruencia» [p. 216]); o contemplando directamente los objetos o personajes que se quieren trasladar al relato: «El novelista decía que él describiría con toda exactitud un faro sin verlo» (p. 172). Nótese, antes de seguir, que Azorín usa repetidamente el verbo penetrar aludiendo a la manera en que la realidad cala en sus personajes («Ya en lo más profundo del novelista ha 
penetrado una especie sutilísima que, a manera de embrión, irá creciendo y desenvolviéndose» [p. 92]; «Y este silencio fue uno de los que en toda su vida más penetraron en el espíritu del poeta» [p. 176]; «La idea del poeta penetró en la sensibilidad de sus compañeros» [p. 274]). Se trata de un modo de tamizar lo que se percibe del entorno para retener tan solo la miga del todo observado. Abro un pequeño paréntesis para recordar una observación de Guillermo Díaz-Plaja (1975: 181) a propósito del aspecto físico de Azorín en sus últimos días:

Le veíamos en nuestras últimas visitas, tan delgado y translúcido que nos parece como si su morir hubiera sido el momento final de su consunción física. La vejez, en efecto, había ido alambicando su figura, convirtiendo en cérea la piel, dejando fláccidos los músculos faciales, como si quisiera dar a entender que solo el espíritu iba a sobrevivir.

Y ese descarnarse del cuerpo, ¿no se puede aplicar al argumento de sus novelas, en que lo intrascendente y lo anecdótico dejan lugar al meollo, es decir a las ideas imperecederas? En Capricho, Azorín mostró su deseo de escribir «una novela de lo indeterminado; una novela sin espacio, ni tiempo ni personajes». En una de las escalas en su travesía a la isla, el poeta ascendió por una «escalerita pina y lóbrega» que lo condujo a una misteriosa estancia en que era posible escuchar el chirrido de una puerta, y sentir cómo se desliza el tiempo: «El tiempo, en este Oriente profundo y milenario, había dejado de existir. Como si todo fuera presente, sin pasado y sin porvenir, sin tiempo ni espacio» (p. 152). No extraña, leída la cita anterior, que Azorín prefiera el presente para la narración, fórmula que le permite transmitir a los lectores la idea de una acción detenida, congelada, que se convierte en universal al ser despojada de toda caducidad. Cuando el poeta se aleja del cúter en un bote, anota Azorín: «En el mundo de los sueños no había sonado ninguna hora» (p. 154); y al llegar a tierra firme, vuelve a apuntar el narrador: «No sabía el poeta si era de día o de noche» (p. 154). Se trata del mismo efecto que engaña a quien contempla la acción pintada sobre un óleo: aunque se intuya el dinamismo de la escena que ha querido representar el pintor, aquél no deja de ser un espejismo, pues lo que penetra en el admirador del cuadro es la esencia de éste que se percibe sobre todo en los matices. Lo poemático sería entonces la suma de realidad e intuición, de manera que la obra trascienda la realidad para convertirse en símbolo. Lo novelesco parte del análisis de la dura realidad, en términos de Pérez de Ayala, y lo poemático de la intuición de quien la observa. El novelista de La isla sin aurora, al intentar describir el mar, duda de si se trata del Mediterráneo o del Atlántico. Decide entonces usar ambos según las escenas, y seleccionar, como el pintor de su paleta, los diferentes 
azules que se le brindan: cobalto, Amberes, Prusia, cinéreo, porque «todos estos azules podían dar la impresión exacta del mar» (p. 86). De igual manera, el novelista busca una playa perdida que se parezca a la que ha contemplado muchas veces en un cuadro de Turner, sobre el que volveré más tarde; al hilo del deseable hallazgo se da cuenta de que «no se puede hablar de añil al tratar de este cielo. El color que le conviene es el de amarillo sucio» (p. 178). En otra parte del libro, se detiene Azorín en el olor, sensación «que no ha entrado todavía en el arte» (p. 160). El poeta quiere llevarse el olor de Oriente para incluirlo en su obra. De este modo, la novela poemática reúne experiencia e intuición ( «sin la facultad de intuir, todo se venía abajo» [p. 88]), suma de ingredientes capaces de alcanzar lo poemático en detrimento de lo narrativo. Lo cotidiano no importa si no sirve para llegar a lo universal y trascendental: «La realidad no era la materia de la poesía» (p. 88). Así resulta que «no es poeta, completo poeta, verdadero poeta, el que se detiene en las apariencias. Detrás de la realidad encimera, con todos sus colores, hay otra» (p. 266). Azorín lo había explicado muy a las claras en un artículo publicado en Destino el 17 de junio de 1944 (La isla sin aurora había aparecido en febrero):

Se suele hablar de las novelas en que no pasa nada: en esas novelas es, precisamente, donde pasan más cosas. La intensidad suple al enredo: en un estado de contemplación, la sensibilidad, con hondo impulso, se aúna con el alma del mundo.

El argumento de la novela se resume en pocas palabras; como se puede colegir de la cita anterior, estamos ante un relato en que «no pasa nada»: Un poeta, un dramaturgo y un novelista viajan a una isla cuya singularidad radica en carecer de aurora. El valor simbólico de estos datos es relevante para entender el sentido de la novela: el viaje remite a la idea de la formación literaria, que aquí coincide también con el parecer cervantino de que lo realmente importante ocurre en el camino antes que en el destino al que uno se dirija. La isla alude a la obra de arte, y por tanto al concepto general de imaginación. Y la aurora es la inspiración inicial del artista. Dice el alicantino: «Sin aurora no hay misterio» (p. 80). Es menester tener presente lo que el propio Azorín afirma acerca de la trascendencia del arte: «Para la perdurabilidad se requiere que la obra, elevándose de lo real, llegue a ser símbolo» (p. 98). No importa, por ello, el caso concreto de este viaje, ni la isla en cuestión («debe de existir una isla sin aurora» [p. 114], afirma Azorín acentuando la probabilidad de su afirmación), ni quiénes son los tales escritores que se embarcan con destino a la isla sin aurora, de ahí que ni siquiera se nombren. Lo que debe recordar el lector de la novela es el símbolo que cada uno de ellos evoca. El hecho de que Azorín haya elegido a un escritor de cada uno de los tres géneros literarios 
tradicionales, permite al autor opinar sobre los diferentes modos de la creación literaria. Concede el alicantino la mayor importancia al poeta: «Sin ideas, imposible ser poeta» (p. 88), ya que «la realidad no es la materia de la poesía» (p. 88), por lo que «el poeta se mueve en la región de lo indiscernible» (p. 96). El novelista, sin embargo, trabaja con la imaginación: «La vida del novelista es el ensueño» (p. 90), y los ensueños de éste son más densos que los del poeta. Menor interés tiene para Azorín la labor del escritor de teatro, ya que este género «es pintura de caracteres», y quienes se dedican a tal menester difícilmente pueden trascender la realidad circundante. Comparando al comediógrafo con el poeta, resulta que este último se mueve en la región de lo ignoto, mientras que aquél lo hace «en el terreno de los hechos concretos» (p. 96). «El teatro no es ingenio, ni es fábula, por original que sea» (p. 100), apunta Azorín para distinguirlo más claramente de la poesía y la novela.

Toda la acción de la novela transcurre en una atmósfera de irrealidad: «Todo es para nuestros amigos como si fuese irreal» (p. 160), dice Azorín de los tres escritores cuando pasean por las callejas de una de las escalas de la travesía; en contacto siempre con la ensoñación: «iY qué es el ensueño sino el móvil de lo real» (p. 140). En el mundo del duermevela triunfa la vaguedad: la isla no tiene nombre; el poeta, el autor de teatro y el novelista tampoco; Azorín ofrece a sus lectores dos llegadas diferentes a la isla; y también dos finales: en el primer capítulo se adelanta la conclusión del relato, según la cual primero se marchó de la isla el poeta, después el novelista, mientras que el comediógrafo se queda en ella; pero en el Epílogo no se aclara si los tres abandonan la isla en el Sin retorno o permanecen en ella. En rigor, La isla sin aurora carece de un final categórico, circunstancia que el propio autor justifica en la novela: «Si toda novela puede ser cambiada en su final, sin que la novela sufra, ¿para qué esforzarse en llegar a ese final?» (p. 92). Para Azorín lo inconcluso llega a ser más esplendente que lo perfecto: «En arte no se sabe lo que es más bello: si lo indeterminado y obscuro, o lo radiante y perspicuo» (p. 92); Entiende el alicantino que «todo desenlace es falso»; y que «lo que se deja en inconcreto es lo más bello», porque «lo incabado tiene su belleza»: En el misterio, por un lado, y en la meditación a que invita, por otro, radica la seducción de lo inacabado: «¿Y cómo no reconocer que en lo inacabado de esa ruta, como en lo inacabado de una obra de arte, existe una atracción que nos seduce?» (p. 186). Se pregunta Azorín, al hilo de estos razonamientos, cómo se hace que lo inacabado sea bello: «Preciso es un ambiente especial que suscite la belleza en torno a la obra» (p. 188). Forzoso será también que comparezca cierta dosis de misterio, ingrediente fundacional de La isla sin aurora. 
Para acentuar el ambiente de misterio y de indeterminación, usa Azorín frecuentes disyuntivas con que deja en vilo al lector: el barco que debe conducir a los tres escritores a la isla «podía ser una goleta, o un bergantín, o un quechemarín» (p. 76), pero observa Azorín que no es una nave rápida, por lo que probablemente «debía de ser zorrera» (p. 78). Sin embargo, se advierte al lector que no baje la guardia, porque «todo podía suceder y podía suceder nada» (p. 76). Incluso los personajes de la novela pueden desvanecerse: «Necesitamos meditar para saber ya a punto fijo si el poeta es una realidad tangible o no» (p. 108). La polifonía contribuye de manera singular a la creación poliédrica del relato. El narrador externo es un hombre erudito y sensible, melancólico y solitario que vive en un estado de ensoñación. La caracterización de esta voz viene dada por la tradicional teoría aristotélica expresada en el Problema XXX, $1^{a}$, en donde el Estagirita se pregunta por qué los hombres inclinados a las artes tienen temperamento melancólico: «Solo en la soledad, solo en el silencio, solo en desprecio del elogio y de la censura, se puede llegar a la verdadera y eterna poesía» (p. 110). Se pregunta Silvano en la carta dirigida a Dríada que se reproduce en el capítulo XXX si «eso que dicen lectura hace entristecer» (p. 254). Insiste Azorín en la soledad que siente el poeta en la aventura del Bósforo, en la última escala de Levante, etc.: «El poeta [...] se vuelve a encontrar solo; solo ante su destino; solo como ante el conflicto del Bósforo» (p. 166), sensación que Azorín recalca machaconamente mediante anadiplosis. El hada del bosque del capítulo XXV también, al describir al poeta, recuerda que éste «ama la soledad» (p. 224) y que «no le place la aprobación del vulgo» (p. 224). Se sirve también el autor de la visita del poeta a un faro para exaltar el símbolo de la soledad encarnado en el torrero con las clásicas connotaciones melancólicas:

Iba a enfrentarse con la soledad prístina, la soledad que se defiende con ardimiento, la soledad que está por encima de todas las demás soledades y que es la esencia de toda soledad (p. 172).

Esta, probablemente, fuera la idea con que Azorín pergeñó el temperamento del narrador en tercera persona; y no duda en parafrasear al Estagirita en el arranque del citado Problema: «iAcaso todos los que se dan excesivamente a la lectura son hoscos y zahareños?» (p. 254). A esta voz hay que sumar la de los tres artistas: el poeta, el novelista y el escritor de teatro, que expresa cada uno de ellos su opinión sobre los asuntos que les salen al paso. Se combina así el uso de la primera persona, el monólogo y las digresiones con el del diálogo dramático. Comparecen asimismo las voces de personajes históricos (Gaspar Rico y Manuel Rodríguez) y de personajes fabulosos (la ondina, el fauno, el can hablador y el hada). En realidad, cada uno de los narradores del relato 
de Azorín cuenta al lector su propia percepción de la realidad, pero quizás lo que más desconcierta a los lectores es que la voz del narrador exógeno, el que identificamos con el autor de la novela, titubee a la hora de establecer los hechos y la sucesión lógica y cronológica de los mismos. Ese afán por poner en un mismo plano, al menos de autoridad, al autor y a sus personajes se explica por el hecho de que Azorín pretende que sea el lector, en última instancia, quien elija las opiniones y versiones de los hechos que más le satisfagan, dejando claro que ninguna de ellas por separado constituirá la verdad absoluta.

A la vaguedad en la narración y la concurrencia en ella de diversas voces, hay que añadir la idea de la imagen artística del mundo, que Azorín desarrolla a sus anchas en el capítulo XVIII («La playa perdida»), aunque hay otras alusiones en el libro, como sucede en la parte $\mathrm{xx}$, cuando el poeta recuerda que el novelista ya había contemplado el paisaje que ahora tiene ante sus ojos en «algún cuadro de pintores holandeses» (p. 192), o más intensamente en la XXXV, en el momento en que la ondina parlera dice al poeta que a él y a sus compañeros debería sobrarles con las auroras que poetas y pintores han pintado (p. 286). El escritor de Monóvar describe con fruición la obra de Turner The evening star (1830), cuadro también aludido en Capricho: «El cuadro de Turner lo ha contemplado él [el novelista] muchas veces, no en Londres, sino en París» (p. 178). La luz vespertina de la obra quedó fijada en el espíritu del novelista, quien busca en la realidad una estampa que emule a la pintada por Turner, pero sin éxito: «Todas las playas que ha ido viendo [el novelista] no tienen el misterioso hechizo de la playa perdida» (p. 180). Cuando, al final, con el catalejo, el personaje atisba una posible playa que sea reflejo de la inmortalizada por el pintor inglés, un detalle, contado como al desgaire, tiene la máxima importancia:

A medida que se acercaba a la playa iba viendo que todo, en la arena y en el cielo, coincidía con su ideal. Sí, aquella era su playa, con su estrella y con la figura de un hombre que va a complacer a un perrito. Y arriba luce con misterio la estrella de la tarde: the evening star. No cabe duda; es todo conforme a sus deseos. $Y$ entonces ocurre una cosa singular; siendo todo lo mismo, no es todo idéntico. Falta la aureolización del arte (p. 180). 


\section{The Evening Star}

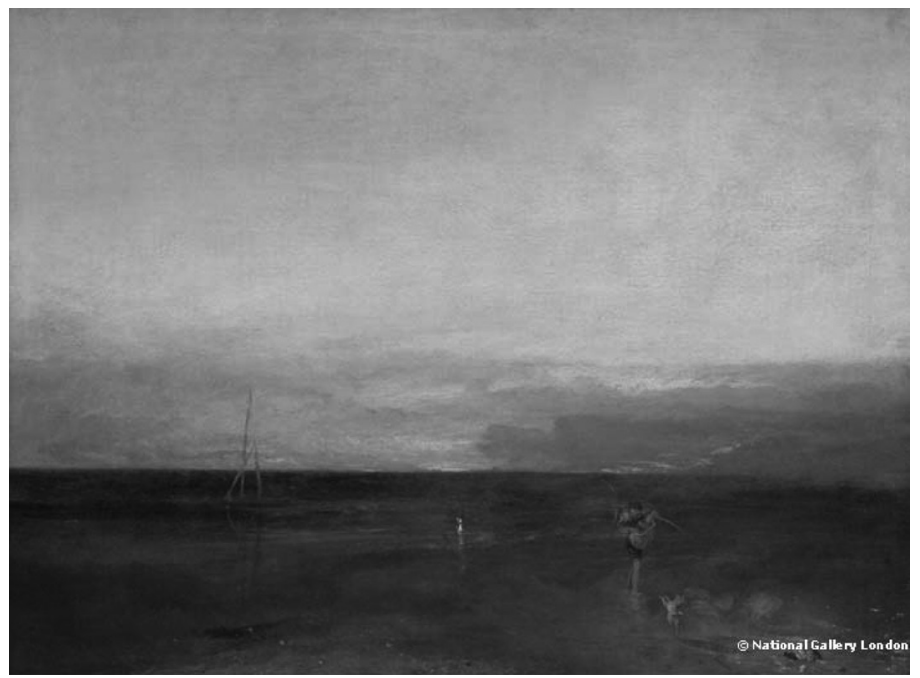

La ékphrasis, tan apreciada por Azorín, representa muy bien su idea de la superioridad del arte frente a la vida:

Turner con su ingenio ha sabido remontarse sobre la Naturaleza. La Naturaleza la tiene allí tal como la ha pintado Turner, y el cuadro del pintor es más bello que este cuadro auténtico de la Naturaleza (p. 180).

Dicho argumento es esgrimido frecuentemente por Azorín con lujo de matices. El artista hace inmortales las acciones humanas: «El arte es imperecedero (la acción más noble solo pervive gracias a la mano de un escritor»; la invención poética es un acto de creación: «[La isla] si la ha inventado algún poeta, tendrá realidad» (p. 128); y el arte no es subsidiario de la realidad: «Lo que inventan los poetas es más cierto que lo que existe en la realidad» (p. 134). El escritor alicantino desarrolla con lucidez y belleza la idea del trabajo del artista, que emula la faena del artesano: «Ningún deporte más distraído que el de una carpintería, un telar o una fragua» (p. 228). La imagen de un taller donde se va dando forma a los objetos deseados, con las manos y las herramientas a su alcance, recuerda el quehacer del artista en el momento de emprender su nueva obra. Igual que éste, el artesano debe moderar su ímpetu en la ejecución de su labor: «No malrotemos nuestras fuerzas [exclaman el poeta, el novelista y el autor dramático]; el espectáculo de una fuerza que llega a su culmen violentamente, es un espectáculo inestético» (p. 230). El placer, en la opinión de Azorín, de la admiración estética estriba fundamentalmente en 
la medida y proporción, ideas que tienen su raíz en la necesidad del artista de «limitarse», asunto al que me referí arriba.

La isla sin aurora, en fin, es una hermosa novela poemática en que su autor compila sus ideas sobre la creación artística y el placer estético, que había ido desgranando a lo largo de su vida, consciente ya a esas alturas de que «la juventud, que se ha marchado, capitán, para no volver nunca» (p. 136), como dice el poeta a Pasquier antes de iniciar la travesía a la isla. Como si se tratara de su propio autorretrato, Azorín resume en un fogonazo el argumento de una vida toda: «El poeta tenía ahora juventud, y con la fuerza juvenil trabaja; no la tendría cuando pasaran años y su vida fuera como uno de estos utensilios aquí hacinados» (p. 166), dice en la última escala de Levante en que el poeta halla en una tienda sombría «muebles viejos, porcelanas, plata labrada, hierros forjados, telas de damasco o de lana antiguas o maltrechas» (p. 166). La novela, en definitiva, más que un género literario, supuso para Azorín un género de vida. Y la poesía, antes que un molde concreto, representa la esencia de seres y objetos. El verdadero escritor debe romper el caparazón de lo anecdótico para alcanzar el verdadero y universal significado de nuestra especie. Cada artista tiene que emprender travesía a su propia isla. Y cuando consiga desembarcar allí, al menos, habrá aprendido que la obra más importante de un escritor es el mismo proceso de su realización en que, como el artesano en su telar, el autor va tejiendo cada uno de los mimbres de su ilusión, que es el «alma del mundo», en palabras del maestro levantino. Tal es el legado de Azorín a la juventud creadora.

\section{BIBLIOGRAFÍA}

Albert, M. (2001), «Azorín y los narradores de vanguardia: en torno a La isla sin aurora», en AA.VV., Azorín et le Surréalisme, Le Pont du Rôle-Gardonne, Fédérop, pp. 435-449.

Amorós, A. (1979), Introducción a la novela contemporánea, Madrid, Cátedra. AzCoAGA, E. (1944), reseña a La isla sin aurora, La Estafeta Literaria, 7, p. 13.

Azorín (1944), La isla sin aurora, Barcelona, Destino.

- (2006), La isla sin aurora, ed. y trad. al italiano de Renata Londero, Nápoles, Liguori Editore.

- (2008), La isla sin aurora, ed. de Renata Londero, Madrid, Biblioteca Nueva.

Baquero Goyanes, M. (1955), «La novela española de 1939 a 1953», Cuadernos Hispanoamericanos, 67, pp. 81-95.

CAStellet, J. M. ${ }^{a}$ (1963), «Veinte años de novela española (1942-1962)», Cuadernos Americanos, CXXVI.

Díaz-PlajA, G. (1975), En torno a Azorín, Madrid, Espasa Calpe. 
DiEGO, G. (1949), reseña a La isla sin aurora, ABC (16 de febrero).

FERnÁNDEZ Almagro, M. (1944), reseña a La isla sin aurora, ABC (28 de mayo). García De Nora, E. (1958), La novela española contemporánea, Madrid, Gredos. Hernández VAlCÁRCEL, C. y C. EsCudero MarTínez (1986), La narrativa lírica de Azorín y Miró, Alicante, Caja de Ahorros de Alicante y Murcia.

LONDERo, R. (1997), Nell'officina dello scrittore. I romanzi di Azorín fra gli anni Venti e Quaranta, Padova, Unipress.

LOZANO MARCO, M. Á. (1983), Del relato modernista a la novela poemática: la narrativa breve de Ramón Pérez de Ayala, Alicante, Universidad de Alicante y Caja de Ahorros Provincial de Alicante.

MAINER, J.-C. (1983) [1967], «Para un análisis formal de Capricho y La isla sin aurora», en D. Villanueva (ed.), La novela lírica, I. Azorín, Gabriel Miró, Madrid, Taurus, pp. 176-182.

Martínez CaChero, J. M. ${ }^{a}$ (1945), Novelistas españoles de hoy, Oviedo, Sindicato Español Universitario.

- (1960), Las novelas de Azorín, Madrid, Ínsula.

- (1973), La novela española entre 1939 y 1969. Historia de una aventura, Madrid, Castalia.

- $\quad$ (1979a), «Novelistas jóvenes y panorama editorial en la década de los cuarenta», en Estudios ofrecidos a Emilio Alarcos, vol. IV, Oviedo, Universidad, pp. 479-494.

- (1979b), Historia de la novela española entre 1936 y 1975, Madrid, Castalia.

- (1997), La novela española entre 1939 y el fin de siglo: historia de una aventura, Madrid, Castalia.

MuÑoz CORTÉS, M. (1944), reseña a La isla sin aurora, Escorial, 42, pp. 306-311. PANERO, L. (1944), reseña a La isla sin aurora, Arriba (2 de abril).

Ramos Ortega, M. J. y Ana-Sofía Pérez Bustamante (eds.) (1995), La literatura española alrededor de 1950: panorama de una diversidad, Cádiz, Universidad.

Sobejano, G. (1975), Novela española de nuestro tiempo, Madrid, Prensa Española. SOldevilla Durante, I. (2001), Historia de la novela española (1936-2000), Madrid, Cátedra.

YNDURÁIN, F. (1952), «Novelas y novelistas españoles, 1936-1952», Rivista de Letterature Moderne, enero-marzo, pp. 279-284.

Fecha de recepción: 18 de diciembre de 2008.

Fecha de aprobación: 2 de febrero de 2009. 